\title{
Variação linguística e ensino de língua no livro didático
}

\section{Linguistic variation and language teaching in the teaching book}

\author{
Rodrigues de Souza Bortolozzo ${ }^{1}$ \\ https://orcid.org/0000-0002-7928-475X \\ Jocineide Macedo Karim² \\ https://orcid.org/0000-0002-7928-475X
}

Resumo: A Pesquisa tem o objetivo descrever como o ensino de língua é abordado em duas coleções de livros didáticos de Língua Portuguesa do Ensino Médio, concebida como única ou se permite variação. Como diz Bortoni-Ricardo (2005), a variação faz parte da natureza da linguagem e, é resultado da diversidade de grupos sociais e da relação que esses grupos mantêm com as normas linguísticas. Trata-se de uma pesquisa descritiva, de cunho qualitativo, que referencia suas características através da observação e do levantamento de dados. O resultado apresentou contrapontos diferentes. O Livro Didático Língua Portuguesa (2013), aborda as questões de língua, variação e preconceito linguístico, enquanto o livro didático de Língua Portuguesa: linguagem e interação (2014), não aborda essas respectivas questões.

Palavras-chave: Sociolinguística; Ensino; Livro Didático; Variação; Preconceito Linguístico.

Abstract: The research aims to describe how language teaching is approached in two collections of textbooks of Portuguese Language of High School, conceived as unique or allows variation. As Bortoni-Ricardo (2005) says, variation is part of the nature of language and is a result of the diversity of social groups and the relationship that these groups maintain with linguistic norms. It is a qualitative descriptive research that references its characteristics through observation and data collection. The result presented different counterpoints. The Portuguese Language Didactic

\footnotetext{
${ }^{1}$ Universidade do Estado de Mato Grosso. E-mail: rodriguesbortolozzo@hotmail.com 2 Universidade Estadual de Mato Grosso do Sul. E-mails: jocineidekarim@yahoo.com.br / jocineidemacedokarim@gmail.com
} 
Book (2013) addresses the issues of language, variation and linguistic prejudice, while the Portuguese language textbook: language and interaction (2014) does not address these questions.

Keywords: Sociolinguistics; teaching; textbook; variation; linguistic prejudice.

\section{Introdução}

A Língua está relacionada aos fenômenos comunicativos, isto é, onde há comunicação, há linguagem. Assim, em consonância com as inúmeras práticas de linguagem, que circulam em diversas esferas sociais, os usos da língua são múltiplos também e uma aula de Língua Portuguesa não pode privilegiar apenas o ensino de Gramática Normativa, com prescrições de regras padrão sem considerar as variedades de língua que o aluno traz para a sala de aula, oriundas de suas práticas de linguagem fora da escola.

Visto que, cada um de nós começamos a aprender a língua em casa em contato com a família e com as pessoas que nos cercam. No contato com outras pessoas, no dia-a-dia, na rua, no trabalho, na escola, observamos que nem todos os indivíduos falam como nós, isso ocorre por diferentes razões: pelo fato de a pessoa ser de outra região, pela diferença de idade, por possuir maior ou menor grau de escolaridade, por pertencer a diferentes classes sociais. Essas diferenças no uso da língua constituem as variedades linguísticas. Dessa forma, habitamos numa sociedade de comunicação generalizada, de modificações velozes e inevitáveis. As mudanças acontecem em todos os lugares, em casa, nas ruas, nas Universidades, na linguagem formal das palestras e conferências dos discursos de grandes membros da sociedade, com modos de fala particulares. As transformações ocorrem também nas escritas, sejam feitas com uma simples caneta ou com o uso enigmático de computadores. Das simples e pequenas frases aos importantes documentos, nada permanece estático no espaço, ou melhor, as mudanças são feitas de acordo com o tempo, "modificadas naturalmente" e ainda as que são determinadas com unificação ortográfica, geradas por lei.

A ideia de investigar a maneira como os livros didáticos de Língua Portuguesa abordam as questões das variedades linguísticas surgiu com a experiência do Estágio Curricular Supervisionado. Nesse contato com os alunos em sala de aula, deparamo-nos algumas vezes com o preconceito à variação da língua. Isso de certo modo nos instigou a investigar como o livro didático de Língua Portuguesa, ainda o principal instrumento de ensino aprendizagem em sala de aula, trabalha a língua em seus conteúdos gramaticais no Ensino Médio, esta que é a última etapa da educação básica. 
Em termos teórico-metodológicos, para a realização desse estudo, nossa investigação tem como proposta de trabalho, analisar, na perspectiva Sociolinguística o ensino de língua através do contexto em $\mathrm{LD}^{3}$ do $\mathrm{EM}^{4}$ cujo objetivo é investigar como a língua é instruída/ensinada nos Livros Didáticos de Língua Portuguesa do EM, se ela é concebida como única, deste modo, homogênea ou se permite variação, consequentemente heterogênea.

Nesse sentido, propomos analisar (2) duas coleções de livros didáticos de Língua Portuguesa-LP ${ }^{5}$ do Ensino Médio, procurando conceituar as diversidades que existem na linguagem, suas virtudes em relação ao ensino de variação que ocorre na língua e consequentemente mostrar o impasse que ocorre na educação, caso esse ensino não aconteça e, desse modo contribuir com a discussão do ensino de Língua Portuguesa no Nível Médio do ensino escolar.

\section{A sociolinguística}

Entre os conceitos de Sociolinguística, Bortoni-Ricardo (2014), explica a preocupação dessa teoria.

[...] a Sociolinguística é uma ciência que nasceu preocupada com o desempenho escolar de crianças oriundas de grupos sociais ou étnicos de menor poder econômico e cultura predominantemente oral. Seu desenvolvimento foi pautado por dois princípios: o relativismo cultural ${ }^{6}$ e a heterogeneidade linguística inerente e sistemática. ${ }^{7}$ (BORTONI-RICARDO, 2014, p. 157).

A disciplina se chama "Sociolinguística" porque estuda a língua como um fenômeno social, isto é, referente aos comportamentos, ações e situações de falares notado nas comunidades.

Consequentemente, através do exposto, citamos o entendimento de Mollica (2003), no que diz respeito à Sociolinguística:

\footnotetext{
${ }^{3}$ A partir desse momento será utilizado LD no lugar de Livro Didático.

${ }^{4}$ A partir desse momento será utilizado EM no lugar de Ensino Médio.

${ }^{5}$ Nesse trabalho a sigla LP será utilizada no lugar de Língua Portuguesa.

${ }^{6}$ Segundo o relativismo cultural, nenhuma língua ou variedade de língua, em uso em comunidades de fala, deveria ser considerada inferior ou subdesenvolvida, não obstante o nível da tecnologia ocidental que aquela comunidade tenha alcançado.

${ }^{7} \mathrm{~A}$ heterogeneidade inerente e ordenada, que está na raiz da Sociolinguística, postula que toda língua natural é marcada pela variação, a qual não é assistemática. Pelo contrário, os recursos de variação, que toda língua natural oferece, estão sistematicamente organizados em sua estrutura e contribuem para tornar a comunicação entre os falantes mais produtiva e adequada. (BORTONI-RICARDO, 2014, p. 157).
} 


\begin{abstract}
A Sociolinguística é uma das subáreas da Linguística e estuda a língua em uso no seio das comunidades de fala, voltando à atenção para um tipo de investigação que correlaciona aspectos linguísticos e sociais. Esta ciência se faz presente num espaço interdisciplinar, na fronteira entre língua e sociedade, focalizando precipuamente os empregos linguísticos concretos, em especial os de caráter heterogêneo. (MOLLICA, 2003, p. 9).
\end{abstract}

A Sociolinguística, também é conhecida como Teoria da Variação e Mudança, é o ramo da Linguística que estuda a relação entre a língua e sociedade, deste modo é o estudo descritivo, exposto e retratado do efeito de qualquer e todos os pensamentos da sociedade, incluindo as normas culturais, expectativas e contexto, na maneira como a linguagem é usada e os efeitos do uso da linguagem na comunidade, na sociedade. É preciso compreender esses efeitos que não se encerram somente no tempo, mas também se manifestam no espaço, nas camadas sociais e nas representações estilísticas. Afinal, a Sociolinguística ocupa-se de questões como variação e mudança linguística, contato linguístico, línguas minoritárias, bilinguismo, política e planejamento linguístico, entre outras.

Segundo Sousa (2005, p. 153), os estudos Sociolinguísticos foram consolidados "depois dos anos 60 com a realização de um congresso na Universidade da Califórnia, no estado de Los Ângeles, Estados Unidos", organizado por William Bright, e contou com a participação de importantes figuras nos estudos da Sociolinguística mundial: William Labov, Dell Hymes e John Gumperz, dentre outros. Os estudos apresentados neste congresso partiam da presunção de que a Sociolinguística deveria confirmar a covariação sistemática das variações linguísticas e sociais, quer dizer, associar as variações linguísticas observáveis em uma comunidade às diferenciações existentes na estrutura dessa mesma sociedade. Através deste, observamos que fatos sociais da língua, já chamavam a atenção desde os estudos de Saussure, mas, apenas nos anos 60 os estudiosos iniciaram os estudos aplicadamente em relação à língua e à sociedade. Todavia, foi com os estudos de William Labov, um percursor dos estudos Sociolinguísticos, que o termo Sociolinguística se fortaleceu e estabeleceu-se, pois ele persistiu na relação da língua e sociedade.

O que queremos dizer, é que a Sociolinguística, surgiu renovando os estudos anteriores, que referenciavam a língua como homogênea, por um método teórico metodológico que interpelou uma nova e original abordagem referente à existência da variação, ocasionado por pressões sociais e linguísticas.

É importante situar as contribuições gerais da Sociolinguística ao ensino de língua, do conhecimento abastecido pelos pressupostos dessa linha teórica, assim fazemos alusão ao menos a três grandes contribuições segundo Martins, Vieira e Tavares (2016): 
(i) definição apurada de conceitos básicos para o tratamento adequado dos fenômenos variáveis; (ii) reconhecimento da pluralidade de normas brasileiras, completo tecido de variedades em convivência; (iii) estabelecimento de diversas semelhanças entre o que se convencionou chamar "norma culta" e "norma popular", não obstante os estereótipos linguísticos facilmente identificados pela maioria dos falantes. (MARTINS et al., 2016, p. 10).

Consequentemente, devemos nos atentar e nos desfazer de noções/ideias préconcebidas. É necessário e fundamental, esquecer de que a ideia da língua é uma estrutura pronta/acabada, que está correta, que ela não muda, varia e transforme-se. Dessa forma, percebemos que a língua/linguagem determina uma relação de ir e vir com a comunidade, e que sem ela, o homem não se organiza socialmente, quer dizer, que a organização social depende da língua e vice-versa, ou seja, vão variando, mudando, transformando e construindo palavras, discursos e ideais.

Consideramos, portanto, que a Sociolinguística tem o importante papel de difundir a realidade linguística com seus significativos estudos sobre as variedades existentes na Sociedade, pois a língua que proferimos contribui para definir quem realmente somos.

\section{Algumas considerações sobre o livro didático}

Aparentemente, parece ser uma temática simples, mas não é, ao passo em que falamos no livro didático, é natural e espontâneo vincular a todo e qualquer material impresso que circulam nas escolas. Talvez seja pela popularidade e simplicidade na existência do contexto escolar, que não atraem a importância necessária no que se refere a sua produção e distribuição.

Consequentemente, o livro didático, repetidamente é caracterizado como um objeto impresso, apenas para fins escolares, quer dizer, é maquiado com um encadeamento de produção, reprodução unicamente com qualidades particulares, o que não deveria ser, pois, o livro didático não é apenas um suporte de aprendizagem para o docente em sala de aula, mas, um alicerce para todo o campo de ensino aprendizagem quando aplicado e manipulado em consonância das metas traçadas por qualquer leitor. Só a partir de um reconhecimento real sobre a importância que o livro didático apresenta como um recurso facilitador de aprendizagem, consequentemente será possível construir uma aprendizagem coesa, por se tratar de um referencial, uma fonte de pesquisa que possibilita o aprofundamento dos conteúdos. Isto é, os livros didáticos fazem parte da cultura de todo corpo social e, ao longo de tantas mudanças/transformações que ocorrem na comunidade, sociedade, ele até então, possui uma função relevante para a aprendizagem da criança e do adolescente, quer dizer, do aluno em si, como mediador na construção da aquisição do conhecimento. 
Dessa forma, sabemos que os livros são um dos recursos mais utilizados dentro de um ambiente escolar, e que no cenário da educação brasileira, ele é umas das principais ferramentas de apoio aos professores e alunos de redes públicas e privadas, isto é, um objeto indispensável para milhões de pessoas que buscam um aprendizado de forma igualitária e significativa, ou seja, um amplo desenvolvedor de sabedoria e conhecimento.

A esse respeito, Bagno (2013), enfatiza:

Os livros didáticos constituem, em muitos ambientes escolares, sobretudo no universo do ensino público brasileiro, a principal, quando não única, ferramenta para o processo de letramento não só dos alunos e, muitas vezes, de suas famílias, como também dos próprios docentes. (BAGNO, 2013, p. 7).

Dessa forma, acreditamos na importância que o livro se faz em sala de aula, de forma que sendo ou não, ferramenta única, ele é um apoio viável a toda rede escolar. A vista disso, citamos Libâneo (2002), sobre a seguinte indagação: qual a importância do livro didático?

[...] naturalmente, em primeiro lugar, tem uma importância pedagógica por ser parte do processo da educação e do ensino. Ele sistematiza o conhecimento científico, transforma o saber científico em saber escolar, em saber para ser ensinado na escola. Em segundo lugar, tem importância política e cultural. Política, porque o livro didático transmite valores e atitudes, isto é, modos de pensar e agir, ideias, opiniões, modos de ver as coisas, preconceitos que podem estar expressando o ponto de vista de determinados grupos sociais economicamente privilegiados. (LIBÂNEO, 2002 p. 127).

Hoje, a responsabilidade é do Programa Nacional do Livro Didático $\left(\mathrm{PNLD}^{8}\right)$, como diz Bagno (2007), “o PNDL é uma instância privilegiada em que os resultados das pesquisas empreendidas nas boas Universidades exercem saudável influência na pratica pedagógica", quer dizer, que tem por intuito regular as escolas públicas de ensino Fundamental e Médio com livros didáticos e acervos de obras literárias, obras complementares e dicionários, isto é, comprando e distribuindo obras didáticas aos alunos do ensino Fundamental e Médio, na modalidade regular ou Educação de Jovens e Adultos (EJA). Dessa forma, a execução do PNLD

\footnotetext{
${ }^{8}$ O Programa Nacional do Livro Didático (PNDL) tem o propósito de abastecer as escolas públicas de ensino fundamental e médio com livros didáticos e conjunto de obras literárias, obras complementares e dicionários. O PNLD é realizado em ciclos trienais alternados, ou seja, a cada ano o FNDE adquire e distribui livros para todos os alunos de determinado ciclo de ensino, repõe e integraliza os livros reutilizáveis para outros períodos.
} 
Ensino Fundamental (regular) e do PNLD Ensino Médio (regular e EJA) segue os passos abaixo, segundo o Programa do FNDE:

Adesão: As escolas federais e os sistemas de ensino estaduais, municipais e do Distrito Federal que desejem participar dos programas de material didático deverão manifestar este interesse mediante adesão formal, observados os prazos, normas, obrigações e procedimentos estabelecidos pelo Ministério da Educação. O termo de adesão deve ser encaminhado uma única vez. Os beneficiários que não desejarem mais receber os livros didáticos precisam solicitar a suspensão das remessas de material ou a sua exclusão do (s) programa (s). A adesão deve ser atualizada sempre até o final do mês de maio do ano anterior àquele em que a entidade deseja ser atendida;

Editais: Os editais que estabelecem as regras para a inscrição do livro didático são publicados no Diário Oficial da União e disponibilizados no portal do FNDE na internet;

Inscrição das editoras: Os editais determinam o prazo e os regulamentos para a habilitação e a inscrição das obras pelas empresas detentoras de direitos autorais;

Triagem/Avaliação: Para constatar se as obras inscritas se enquadram nas exigências técnicas e físicas do edital, é realizada uma triagem pelo Instituto de Pesquisas Tecnológicas do Estado de São Paulo (IPT). Os livros selecionados são encaminhados à Secretaria de Educação Básica (SEB/MEC), responsável pela avaliação pedagógica. A SEB escolhe os especialistas para analisar as obras, conforme critérios divulgados no edital. Esses especialistas elaboram as resenhas dos livros aprovados, que passam a compor o guia de livros didáticos;

Guia do livro: O FNDE disponibiliza o guia de livros didáticos em seu portal na internet e envia o mesmo material impresso às escolas cadastradas no censo escolar. O guia orientará a escolha dos livros a serem adotados pelas escolas;

Escolha: Os livros didáticos passam por um processo democrático de escolha, com base no guia de livros didáticos. Diretores e professores analisam e escolhem as obras que serão utilizadas pelos alunos em sua escola;

Pedido: A formalização da escolha dos livros didáticos é feita via internet. De posse de senha previamente enviada pelo FNDE às escolas, professores fazem a escolha on-line, em aplicativo específico para este fim, disponível na página do FNDE;

Aquisição: Após a compilação dos dados referentes aos pedidos realizados pela internet, o FNDE inicia o processo de negociação com as editoras. A aquisição é realizada por inexigibilidade de licitação, prevista na Lei 8.666/93, tendo em vista que as escolhas dos livros são efetivadas pelas escolas e que são editoras específicas que detêm o direito de produção de cada livro;

Produção: Concluída a negociação, o FNDE firma o contrato e informa as quantidades de livros a serem produzidos e as localidades de entrega para as editoras. Assim, inicia-se o processo de produção, que tem supervisão dos técnicos do FNDE; 
Análise de qualidade física: O Instituto de Pesquisas Tecnológicas (IPT) acompanha também o processo de produção, sendo responsável pela coleta de amostras e pela análise das características físicas dos livros, de acordo com especificações da Associação Brasileira de Normas Técnicas (ABNT), normas ISO e manuais de procedimentos de ensaio préelaborados;

Distribuição: A distribuição dos livros é feita por meio de um contrato entre o FNDE e a Empresa Brasileira de Correios e Telégrafos (ECT), que leva os livros diretamente da editora para as escolas. Essa etapa do PNLD conta com o acompanhamento de técnicos do FNDE e das secretarias estaduais de educação;

Recebimento: Os livros chegam às escolas entre outubro do ano anterior ao atendimento e o início do ano letivo. Nas zonas rurais, as obras são entregues nas sedes das prefeituras ou das secretarias municipais de educação, que devem efetivar a entrega dos livros. (FNDE, 2017).

[...] - em geral, só a aula do professor não consegue fornecer todos os elementos necessários para a aprendizagem do aluno, uma parte deles como problemas, atividades e exercícios pode ser coberta recorrendo-se ao livro didático;

- Muitas escolas são limitadas em recursos como bibliotecas, materiais pedagógicos, equipamento de duplicação, vídeos, computadores, de modo que o livro didático constitui o básico, senão o único recurso didático do professor. (DANTE, 1996, p. 52).

O livro didático é uma ferramenta indispensável e substancial de ensino aprendizagem adotado pelas escolas públicas, "o livro didático passou a ser o principal, em muitos casos, o único instrumento de apoio ao trabalho docente" (DANTE, 1996, p. 52). Nessa perspectiva, Dante (1996) apresenta várias razões para justificar a importância do livro didático.

Certamente, o livro didático, mesmo sendo representado na maioria das vezes, como uma ferramenta cultural que gera controvérsias e ocasiona críticas, tanto positivas quanto negativas, ainda é fundamental, indispensável e considerado um instrumento essencial no processo de escolarização, pois, ele pode oferecer diversas contribuições tanto para alunos quanto para professores. Consideramos e destacamos novamente a importância desse material pedagógico, o livro didático vai muito além de ser apenas um simples manual escolar, ele torna o conhecimento em suas manifestações de modo simples que deixam marcas definidas, registradas, marcadas nas memórias dos alunos e a todos que utilizam esse material.

Dessa forma, Libâneo (2002), acrescenta:

[...] nele encontra-se organizado e sequenciado o conteúdo científico da matéria supostamente correto. Através dele o professor continua aprendendo, ganhando mais segurança para o trabalho na sala de aula. Para o aluno é uma fonte de informação imprescindível por conter o saber sistematizado da matéria escolar, além de ser meio para o estudo individual, revisão e consolidação da matéria. Se bem utilizado pelo 
professor, o livro didático ajudará os alunos a lidar com a informação, a formar conceitos, a desenvolver habilidades intelectuais e estratégias cognitivas, que são os objetivos de um ensino adequado para o nosso tempo. (LIBÂNEO, 2002, p. 131).

Como o livro didático têm um papel fundamental no processo ensino aprendizagem é de suma importância à qualidade, desde a sua fabricação até a sua escolha pelos professores nas escolas. Nesse caso, convém citar Soares (2002), ao lembrar que até recentemente, o conteúdo do livro didático de Língua Portuguesa eram apenas os textos de autores clássicos. Eram atribuídos, assim, valor aos escritores e se esquecia do vínculo que deveria haver com as necessidades vivenciadas pelos alunos. Hoje, essa realidade vem mudando, mesmo que seja lentamente, uma vez que os livros já contêm uma diversidade de textos que abrangem os diferentes falares e as diferentes características regionais do nosso País (Brasil).

\section{Processos de escolha dos livros didáticos}

Uma das principais diferenças entre os seres humanos e outros animais é a nossa capacidade de reconhecer e utilizar a linguagem, diante disso se faz necessário compreender que tanto a escola, o livro didático e os professores que trabalham nela e utilizam essa ferramenta de ensino aprendizagem, devem empenhar-se em um conceito de que a língua é um fato social, que mantém a interação entre as pessoas, quer dizer, as linguagens foram estruturadas historicamente com condições de interações entre pessoas, com o processo de socialização, gerando uma interação social. Nesse sentido contextualizamos o conceito de socialização:

[...] a socialização não é própria apenas do ser humano, mas, nele, ela apresenta-se como natural, justifica-se como necessidade de sobrevivência e materializa-se na constante interação. Por meio de gestos corporais, de expressões verbais e visuais, conscientes e/ou inconscientes, todos contendo um lado afetivo, a projeção social típica do ser humano concretiza-se. Todas essas manifestações simbólicas produzem efeitos no outro e são reconhecidas como linguagem. (SEE, 2012, p.64).

Diante da utilização da linguagem, Abaurre e Pontara afirmam:

Reconhecer a linguagem como uma atividade humana significa dar a ela a devida dimensão na nossa relação com o mundo. Dentre todas as linguagens, é a língua natural - aquela que falamos - que nos dá identidade, permite nomeação do mundo a nossa volta, participa da 
Desse modo, destaca-se a importância do livro didático, no ambiente escolar, pois é na escola que sua aprendizagem sistemática e formal será motivada. Lajolo (1996), menciona a importância da escola e seu conjunto de objetos envolvidos:

\begin{abstract}
A escola é um lugar especial. Também especial é o material escolar, que se pode definir como o conjunto de objetos envolvidos nas atividades-fim da escola. Tudo aquilo que ajuda a aprendizagem que cumpre à escola patrocinar-computadores, livros, cadernos, vídeo, canetas, mapas, lápis de cor, televisão, giz e lousa, entre outras coisas - é material escolar. (LAJOLO, 1996, p. 03).
\end{abstract}

Entre esses tantos objetos citados acima, compreendemos, relevamos que são os livros didáticos que nos conduz para outras dimensões através das suas escritas, atividades, diferenças textuais, estruturas gramaticais, desenvolvendo-nos as habilidades de escrita e leitura, quer dizer, uma das ferramentas mais importantes para aprendizagem em todos os graus de ensino na educação brasileira.

Independente do livro didático ou da disciplina abordada, o que se constata é que o livro didático constitui um elo importante na corrente do discurso da competência: é o lugar do saber definido, pronto, acabado, correto e, dessa forma, fonte última (e às vezes, única) de referência (SOUZA, 1999, p. 27-28).

Consequentemente, selecionamos as coleções dos livros pelo "contraste" e/ou "dissemelhança" ${ }^{\text {"9 }}$ que ambas as coletâneas apresentam, além da diversificação dos conteúdos, tais como: estrutura gramatical, atividades, papel desafiante de estabelecer hipóteses, confrontar ideias, analisar e comparar pontos de vista, e por fim, de expandir ou não o ensinamento da língua/linguagem e variação linguística considerada um aspecto artístico, estrutural e prático, algo que é parte integrante do homem, quer dizer, de revelar as diversidades e variações constitutivas que existem na língua. Assim como, pelos autores que escreveram as obras, que criam um mundo alternativo, que exploram as palavras, que lhes dão perspectivas e imaginações

${ }^{9} \mathrm{Grau}$ marcante de diferença ou oposição entre coisas da mesma natureza, suscetíveis de comparação, isto é, estado ou qualidade do que é dissemelhante (diferente). 
e também pela formação, abrindo caminhos de aprendizagem através de suas experiências, uma vez que, produzir linguagem é:

\begin{abstract}
[...] trabalhar com valores, conceitos, noções e comportamentos que os justificam e que são comuns aos interlocutores ou do seu conhecimento. Isso é ideologia e torna possível que o que se diz seja compreensível para ambas as partes de interação. Essa plataforma ideológica resulta da pratica social e obedece a condições históricas, conjunturais e culturais. Assim sendo, a produção de linguagem envolve a organização formal e ideológica do dizer de tal maneira que consigamos ser entendidos como queremos sê-lo. (SEE, 2012, p.64).
\end{abstract}

Deste modo, os livros são parte constituinte da vida do homem no decorrer da nossa formação, e que sem eles passamos despercebidos de muitos saberes que às vezes só eles dispõem. E, é com comprometimento, que os livros de Língua Portuguesa tendem a transmitir, ensinar sobre a linguagem, para que as pessoas que vivem em comunidade/sociedade saibam que ocorrem variações na fala dependendo do contexto que estamos participando, para que não ocorra em nenhuma hipótese o preconceito linguístico, ainda assim, podemos concluir com as palavras de Bagno (2007), em que "os principais problemas que encontramos nos livros didáticos de Língua Portuguesa é uma tendência de tratar a variação linguística, em modo geral, como sinônimo de variedades regionais, rurais ou de pessoas não escolarizadas", em outras palavras, esse conceito abordado é menosprezar a fala do próprio povo brasileiro.

\title{
4 A pesquisa
}

Para analisar como os livros didáticos de língua portuguesa lidam com a variação linguística, optamos por um trabalho descritivo, de caráter qualitativo, quer dizer, que descreve suas características e qualidades e/ou deficiências/irregularidade. Segundo Barros e Lehfeld (1990, p. 34) "a pesquisa descritiva é definida como descrição do objeto por meio da observação e do levantamento de dados".

Para análise deste estudo foram selecionadas duas coleções de livros didáticos de Língua Portuguesa, escritos por autores diferentes e ambos de nível médio, como seguem: a) coleção 1, Língua Portuguesa, elaborado por Roberta Hernandes e Vima Lia Martin, pela editora Positivo, $1^{\circ}$ edição, Curitiba, 2013, para alunos do $1^{\circ}, 2^{\circ}$ e $3^{\circ}$ ano do Ensino Médio; e b) coleção 2, o livro Língua Portuguesa: linguagem e interação, elaborado por Carlos Emilio Faraco, Francisco 
Marto de Moura, José Hamilton Maruxo Júnior, pela editora Ática, $1^{\circ}$ impressão, $2^{\circ}$ edição, São Paulo, 2014, do mesmo modo, para alunos do $1^{\circ}, 2^{\circ}$ e $3^{\circ}$ ano do Ensino Médio.

\subsection{Livro didático - língua portuguesa}

O primeiro livro Língua Portuguesa é dividido em 06 unidades, contento 24 capítulos. Numa análise preliminar consideramos como uma importante ferramenta de ensinoaprendizagem ao meio educacional, fazendo com que o aluno seja desafiado, participativo, analista e conhecedor da linguagem, considerada parte integrante e indispensável de nossas vidas, como diz no livro em sua apresentação ao aluno, este livro irá acompanhá-lo em muitos momentos, por isso, ao escrevê-lo buscamos usar uma linguagem acessível, escolher textos motivadores e de gêneros variados (por vezes apresentados em diálogo com obras de artes plásticas, fotografias) e propor atividades interessantes para que você (aluno) possa refletir sobre o Português - a língua que fala e com a qual escreve - e também com as literaturas que são escritas nessa língua.

Julgamos, ainda, um livro com atividades diversas que fornece sentidos aos alunos com as produções de textos, gramática e a literatura, isto é, essa coleção tem o objetivo de fornecer subsídios para a melhor compreensão dos mais variados textos, pois acreditamos que a leitura é capaz de realizar mudanças notáveis, transformando as pessoas em sujeitos mais sensíveis, éticos, criativos e também conscientes da diversidade da língua portuguesa.

A coleção apresentada é um componente curricular da Língua portuguesa que foi escrito para atender alunos especificamente do $1^{\circ}, 2^{\circ}$ e $3^{\circ}$ ano do Ensino Médio. As autoras enfatizam a importância da linguagem e da coleção apresentada, apenas o livro didático do $1^{\circ}$ ano apresenta no capítulo 11 uma abordagem sobre a linguagem e variação linguística, ou melhor, definem as variedades linguísticas, a competência comunicativa, a norma-padrão e as normas urbanas de prestígio, referenciam os linguistas e gramáticos, caracterizam a gíria como uma forma de construção da identidade linguística e evidenciam o preconceito linguístico impregnadas na nossa sociedade.

Dessa maneira, consideramos que o livro do $1^{\circ}$ ano do Ensino Médio desenvolve algumas habilidades de leitura e escrita, promovendo variadas situações discursivas para uma melhor aprendizagem do aluno, visto que, utilizam as estruturas linguísticas adequadas a cada contexto específico, e salientam a importância das variedades da língua.

A seguir, apresentamos as capas dos livros da coleção de Língua Portuguesa: 
Figura 1 - Capas dos Livros didáticos de Língua Portuguesa.

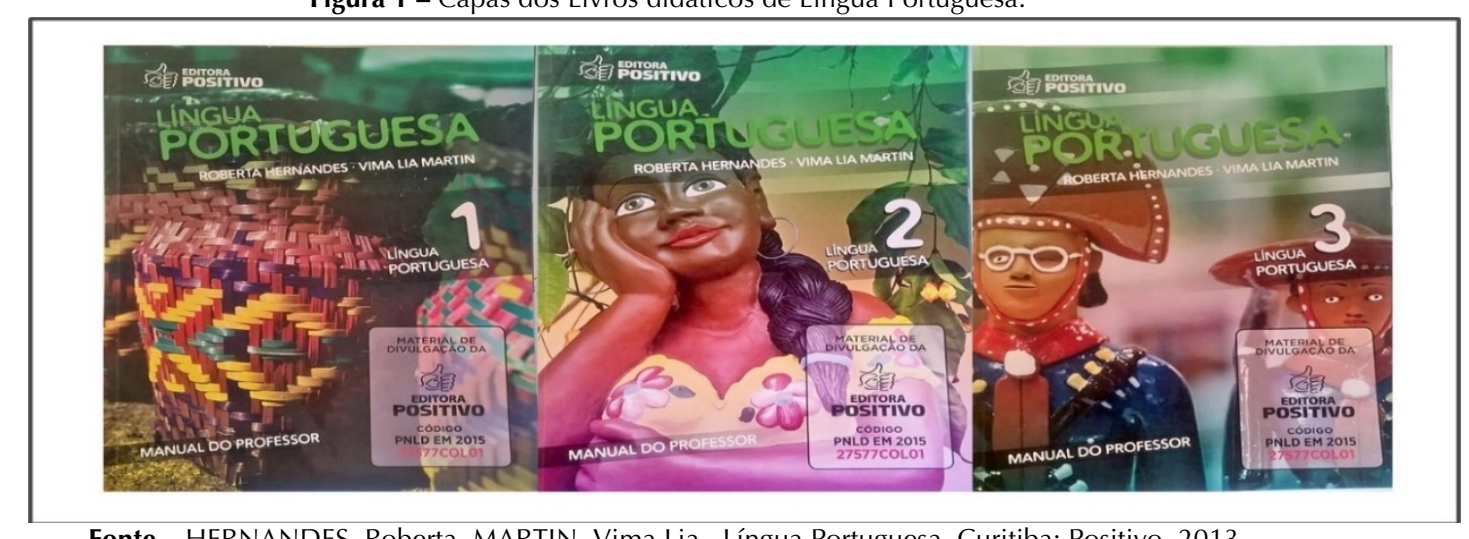

Fonte - HERNANDES, Roberta. MARTIN, Vima Lia. Língua Portuguesa. Curitiba: Positivo, 2013.

Notamos a importância do material e através de suas capas podemos inferir algumas questões que se tornam importantes ao leitor por meio visual. Observamos através da visualização das capas, questões regionais que se fazem presentes, pois vemos nas capas da coleção, as roupas, os personagens, todo um design colaborando para o regionalismo, quer dizer, através desse exposto os autores utilizam de mecanismos gráficos para atentar-se a questões que estão postas dentro dos livros didáticos.

\subsection{Livro didático - língua portuguesa: linguagem e interação}

A segunda coleção de livro didático é intitulada Língua Portuguesa: linguagem e interação, e é dividido em 04 unidades, contendo 12 capítulos. As propostas são tomadas com as linguagens, textos e literatura. Em sua apresentação, o livro condiz, primeiramente, com a leitura de alguns textos, a fim de desenvolver estratégias de leitura, necessária quando é preciso compreender determinados gêneros(s) ou tipo(s) de texto, em seguida, estudará as características desses tipos de texto para entender como se organizam, para que servem em que situações de comunicação costumam ser utilizados. Depois, conhecerá obras literárias que tem relações com os textos estudados, para ajudar o aluno a compreender essas obras literárias. Também há propostas com a linguagem oral e os estudos de gramática - importantes para o aperfeiçoamento da maneira de se comunicar.

A coleção apresentada é um componente curricular da Língua portuguesa que foi escrito para atender alunos especificamente do $1^{\circ}, 2^{\circ}$ e $3^{\circ}$ ano do Ensino Médio e, consequentemente, foi feito para o aluno perceber que estudar a Língua Portuguesa é uma atividade envolvente, 
dinâmica e prazerosa. É um livro bem elaborado com atividades de leitura e compreensão de texto, porém, não traz de forma concreta, explicita e significativa as relações acerca das variações linguísticas. Assim, perguntamos como o aluno pode diversificar variadas formas de linguagem se ele não conhece essas formas? E, ainda, refletimos se o livro didático considerado principal suporte teórico para o aprendizado dos alunos, não menciona sobre as diversas linguagens em nossa comunidade, como o aluno compreenderá as questões que envolvem a variação linguística? Por meio desses questionamentos que defendemos a ideia sobre a importância do livro didático abranger múltiplas formas de linguagens, ou seja, o aluno cresce convivendo com muitas variedades de fala, porém, o que talvez ele não consiga entender é como e porque apenas uma é considerada "correta" e as demais "erradas", isto é, não sabendo e/ou entendendo que existem diferenciações na linguagem, estimulando uma série de preconceitos, pois, o aluno não saberá se expressar de formas diferenciadas dependendo do contexto comunicativo que está inserido.

De modo geral, esta coleção não apresentou em nenhuma fase de ensino, conteúdos em relação ao estudo da Variação Linguística. Nesse caso, podemos considerar que ele foi elaborado com base em uma abordagem estruturalista da língua, isto é, essa visão estrutural concebe a língua como um sistema de elementos relacionados para decodificar sentido, tendo como objetivo, a língua como foco principal e o sistema de regras que o falante deve aprender. No exposto acima, não podemos deixar de mencionar o papel da escola na elitização do ensino, pois, se a escola tem como "missão", referente ao aprendizado da língua, é de suma importância propor estratégias e competências para que se organize uma escolha coletiva, discutindo procedimentos de análises, examinando exemplares de livros solicitados às editoras, considerando o perfil dos alunos e do projeto pedagógico da escola.

Dessa forma, refletimos que a escola tem que se impor de forma mais significativa/qualitativa na elaboração dos livros didáticos, não deixando de lado, assuntos relacionados com a realidade de fala do aluno, buscando sempre, livros que dê ênfase à construção dessa realidade.

A seguir, apresentamos na figura 2, a outra coleção de livros didáticos de Língua Portuguesa: 
Figura 2 - Capas dos Livros didáticos de Língua Portuguesa: linguagem e interação.

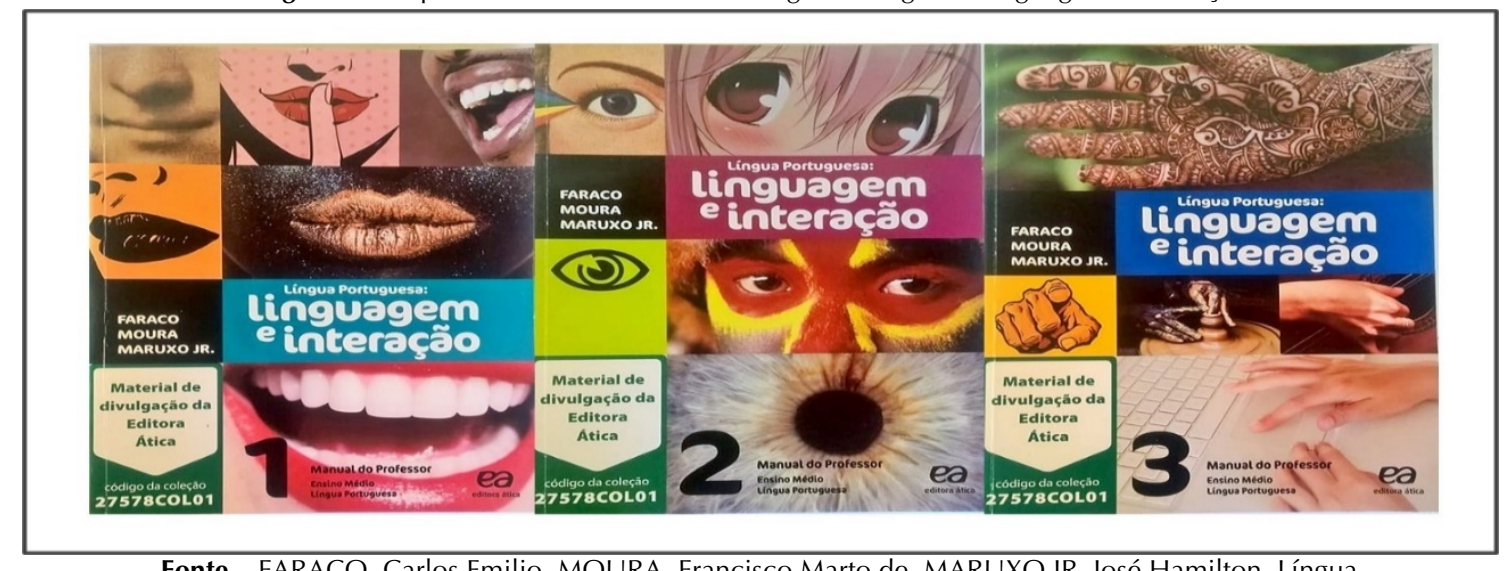

Fonte - FARACO, Carlos Emilio. MOURA, Francisco Marto de. MARUXO JR, José Hamilton. Língua Portuguesa: linguagem e interação - São Paulo: Ática, 2014.

Diferentemente da outra coleção apresentada, o mecanismo gráfico que se apresenta nas capas não condiz ao meio textual, pois observamos modos de interação da língua por gestos través da boca, olhos, mãos. Quer dizer, se há interação da língua, é cabível variadas formas, mas que a coleção não apresenta.

\section{Análise do livro didático}

O conteúdo dos livros didáticos, ainda que unificado, deixa muitas vezes o aluno distanciado do conhecimento necessário e fundamental para o processo de aprendizado sobre a variação linguística e/ou as variações que ocorrem na língua de forma natural. Esse fator compromete a aprendizagem, pois o livro como objeto principal de estudo, aparentemente deixa de considerar as diversidades linguísticas existentes na língua portuguesa e/ou tentam empregar no livro a língua/linguagem como forma única, sem alterações, sem transformações, sem variações etc. Desse modo, procuramos fazer um estudo da variação linguística, apresentada de forma mais ampla, pois, consideramos que, nesse nível escolar os alunos estariam mais acostumados aos estudos da língua e assim, os livros didáticos, apresentariam de maneira mais acentuada esses estudos.

Consideramos esse roteiro abaixo para o desenvolvimento das análises das coleções dos 
livros didáticos de Língua portuguesa. ${ }^{10}$

Como os livros didáticos de Língua Portuguesa consideram a variação linguística exposta nos capítulos e nas demais atividades propostas? Apresentam a existência de várias formas de linguagem?

Para a análise das atividades, escolhemos livros didáticos que abordam a questão da variação linguística definidos pelos PCNs. Como dito acima, a coleção dos livros didáticos de Língua Portuguesa escrito por Hernandes e Martin (2013), abordam essas questões. Nos três livros que comtemplam a coleção, apenas o livro do $1^{\circ}$ ano do EM situa tais ensinamentos. Compreendemos que mesmo que o livro aborda variadas formas, não está bom, e que avançou referente a outros, mas ainda está em uma forma limitada, poderia assim propor mais coisas, marcar o texto, trabalhar em todo o livro, quer dizer, observamos que o estudo da variação linguística sempre aparece de forma separada. Dizemos isso, pois indagamos por que entre tantos capítulos escritos, apenas um é proposto para falar de variação, e ainda de forma sucinta na maioria das vezes, isto é, precisamos de livros didáticos que desenvolva tais conhecimentos em um todo. As atividades contidas nessa coleção consideram, mesmo que limitado, relações de variação na linguagem, competência comunicativa, de normas-padrão e normas urbanas de prestígio, quer dizer, informando e mostrando para o leitor que a variação linguística é um fenômeno próprio das línguas, inerente a elas e que existe uma pluralidade de línguas.

Na coleção de livros didáticos escritos por Faraco, Moura e Maruxo (2014), os autores deixam de considerar a realidade linguística no Brasil. A partir da análise nos livros, percebemos na apresentação que se detém no livro, nas palavras dos autores, que os alunos irão compreender as muitas relações que há entre a linguagem que se utiliza nas situações de comunicação do dia a dia e aquela que deve ser empregada nas situações mais formais, porém, não tivemos essas informações empregadas nesses livros. Assim perguntamos como esse livro foi aprovado se ele não tem nada de critério dos PCNs e do próprio programa PNLD? De tal forma, lembramos que o professor não tem livros diversificados para sua escolha, pois na maioria das vezes, já estão selecionados e impostos pelo próprio sistema. Dessa forma

\footnotetext{
${ }^{10} \mathrm{O}$ roteiro foi elaborado com base nas questões motivadoras de LIMA, Ricardo (2016).
} 
constatamos que o livro está preso na concepção de língua/sistema, e não leva em conta a diversidade/variação linguística, e que o padrão sendo único surge o preconceito linguístico, pois em nenhum momento trabalham a pluralidade de línguas existentes.

A seguir destacamos mais uma indagação que direcionou nossas análises:

A variação linguística se apresenta em todas as seções dos livros ou se apresenta apenas de forma isolada, separada e sucinta?

Nas duas coleções apresentadas em estudo, observamos que a variação linguística se apresenta apenas de forma isolada, separada e sucinta. Nas coleções apresentadas a variação não é trabalhada no livro todo, possuindo entre tantos capítulos apenas um para trabalhar com o tema. Na coleção de livros didáticos escritos por Faraco, Moura e Maruxo (2014), os autores deixam de considerar a realidade linguística no Brasil.

Na coleção dos livros didáticos de Língua Portuguesa escrito por Hernandes e Martin (2013), abordam essas questões, mas como já dito, com apenas um capítulo voltado a tratar dessa temática. Foi percebido ao longo de todo livro que a questão da variação, língua e preconceito linguístico se mantém apenas com atividades para aprender a Gramática Normativa. Indagamos novamente a opinião de que se contém o assunto da variação nos livros didáticos, apenas por uma imposição de órgãos oficiais políticos pedagógicos para apresentar essas questões existentes e importantes que estão relacionadas a língua portuguesa brasileira. Contudo, afirmamos que não está bom pela sucinta abordagem e que deveriam abordar a temática em todo o livro, com outras propostas de atividades, não apenas que ela exista em um único capítulo para atender uma exigência que está postulada em documentos educacionais. Dessa forma, observamos nos livros sempre a questão da variedade linguística de forma separada, o que não poderia ocorrer.

Evidenciamos mais uma questão que direcionou nossas análises:

Os fenômenos da variação linguística exposto na coleção estão adequados a realidade linguística de Mato Grosso?

Foi percebido no capítulo destinado a evidenciar a variação linguística que está na coleção dos livros didáticos de Língua Portuguesa escrito por Hernandes e Martin (2013), que há abordagem desses fenômenos em um contexto geral, não tratando características regionais do Estado de Mato Grosso. Buscamos vários exemplos, mas não encontramos. Mais uma vez 
afirmamos que há uma preocupação com o ensino de língua e variação linguística, visto que o ensino dos fenômenos é exposto em apenas um capítulo e que se referindo a um grande estado, não contém fragmentos alguns dessa região, um livro que estava em uso pouco tempo atrás em uma escola Estadual de rede pública. Em nossa análise verificamos a falta de conteúdos regionais destinados a região, algo que poderia estar presente na aprendizagem de todas as crianças.

Segue abaixo mais uma indagação que direcionou nossas análises:

Há a aplicação dos gêneros textuais que sejam representativos das variações linguísticas abordadas?

Em relação aos gêneros utilizados, há a utilização que pretendem caracterizar as variedades linguísticas. Observações exemplos de variações acerca de verbete abordando o léxico coloquial do português, tirinhas observando o uso linguístico mais espontâneo, tabelas demostrando as variedades menos e mais prestigiadas, poema de patativa do Assaré exibindo a linguagem coloquial, cartum evidenciado o preconceito linguístico, e textos exibindo gírias e a língua. Assim, apresenta trechos de textos linguísticos explicando os fatos da variação e preconceito na língua. Na análise observamos pontos positivos de se ensinar requisitos da língua com os gêneros textuais em que estão presentes em nosso dia-a-dia.

\section{A variação linguística}

Para analisar os livros Didáticos de língua Portuguesa, faz-se necessário destacar as concepções teóricas que conduzem este estudo, assim, iniciamos pelo conceito de variedade que não é tão simples como se parece, sendo de fundamental importância à discussão e preceitos ao longo do tempo feito por alguns estudiosos.

Observamos abaixo nas palavras de Bagno (2007), afirmando que:

[...] a grande maioria das pessoas acha muito mais confortável e tranquilizador pensar na língua como algo que já terminou de se construir, como uma ponte firme e sólida, por onde a gente pode andar sem medo de cair e de se afogar na correnteza vertiginosa que corre lá embaixo. Mas essa ponte não é feita de concreto, é feita de abstrato... O real estado da língua é o das águas de um rio, que nunca param de correr e de se agitar, que descem e sobem conforme o regime das chuvas, sujeitas a se precipitar por cachoeiras, a se estreitar entre montanhas e se alargar pelas planícies. (BAGNO, 2007, p. 36). 
O domínio da língua tem estreita relação com a possibilidade de plena participação social, ela se presta de total importância em nosso dia-a-dia e no nosso convívio em comunidade/sociedade. A língua é um princípio desenvolvido naturalmente com o propósito de difundir pensamentos, ideias através da comunicação e interação com todas as pessoas, logo, ela constitui-se num código mutável que compõe as relações humanas e que, ao mesmo tempo em que sofre alterações/variações, contribui das mudanças na comunidade. Esse recurso social é encarregado pela capacidade de se preservar o conhecimento e de transmiti-lo a outras gerações no decorrer do tempo. É através deste, que percebemos que sem a língua, esse conjunto organizado de elementos, o mundo seria um imenso vazio. Essa ligação natural entre língua, cultura, sociedade, estabelece a organização fundamental nas ações diárias de nossas vidas. Desse modo, as variações acontecem na cultura como também na língua, seja por extinção, ampliação e/ou modificação dos elementos. Elucidamos através das palavras de Almeida Baronas (2014):

\footnotetext{
A variação linguística constitui um fenômeno natural em qualquer língua, entretanto tal fato não é compreendido pela grande maioria da população brasileira que acredita ser a língua do Brasil um objeto homogêneo, inflexível. (ALMEIDA BARONAS, 2014, p. 40).
}

Segundo Labov (1972/2008, p. 215), “a língua é uma forma de comportamento social, pois comunica necessidades, ideais e emoções". Uma nação apresenta diversos traços de identificação, e a língua é um deles e, esta pode variar em certos fatores, tais como o tempo, espaço e nível cultural.

Alguns gramáticos e professores procuram o "ideal da homogeneidade", pois, tentam impor a norma linguística idealizando e querendo que todas as pessoas falem uma única língua, do mesmo modo, sempre do mesmo jeito, o que se torna impossível já que em um país miscigenado como o Brasil, existe uma grande diversidade e variabilidade de português. A respeito das normas cultas e literárias impostas pelos escritores e instituições oficiais, por exemplo, Bagno (2003, p. 16) argumenta que:

[...] se formos acreditar no mito da língua única, existem milhões de pessoas neste país que não têm acesso a essa língua, que é a norma literária, culta, empregada pelos escritores e jornalistas, pelas instituições oficiais, pelos órgãos do poder - são os semlíngua. (BAGNO, 2003, p. 16). 
O que o autor menciona acima, quere dizer, é que não existe uma única língua, idêntica, perfeitamente igual, deste modo homogênea, como tentam empregar, mas, uma língua heterogênea que apresenta um multilinguismo, qualidades e modos diferentes, ou seja, uma grande diversidade linguística que é cheia de variações, não como "as pessoas de um modo geral tem uma ideia de que existe uma língua que é considerada o bem social, que está ao alcance de todos.

Compreendemos que, a variação linguística existe e que, é um fenômeno próprio das línguas, inerente a elas, assim, não é possível dizermos que uma forma variante seja mais ou menos correta que outra, ou melhor, as formas variantes são sempre formas possíveis de usos linguísticos, quer dizer:

\begin{abstract}
A questão não é falar certo ou errado, mas saber qual forma de fala utilizar, considerando as características do contexto de comunicação, ou seja, saber adequar-se às diferentes situações comunicativas é saber coordenar satisfatoriamente o que falar e como fazê-lo, considerando a quem e por que se diz determinada coisa. É saber, portanto, quais variedades da língua oral são pertinentes em função da intenção comunicativa, do contexto e dos interlocutores a quem o texto dirige. Em suma, a questão não é a correção da forma, mas de sua adequação às circunstâncias de uso, ou seja, de utilização eficaz da linguagem, pois falar bem é falar adequadamente, é produzir o efeito pretendido e desejado. (PCN, 1997, p.26).
\end{abstract}

Por esse motivo, precisamos estar cientes da necessidade de saber fazer as adequações possíveis da variedade usada e da situação de comunicação da qual participamos.

Um bom exemplo disso é a tirinha a seguir, extraída do livro Língua Portuguesa. 
Figura 3: A língua como um fenômeno naturalmente variável e heterogêneo.

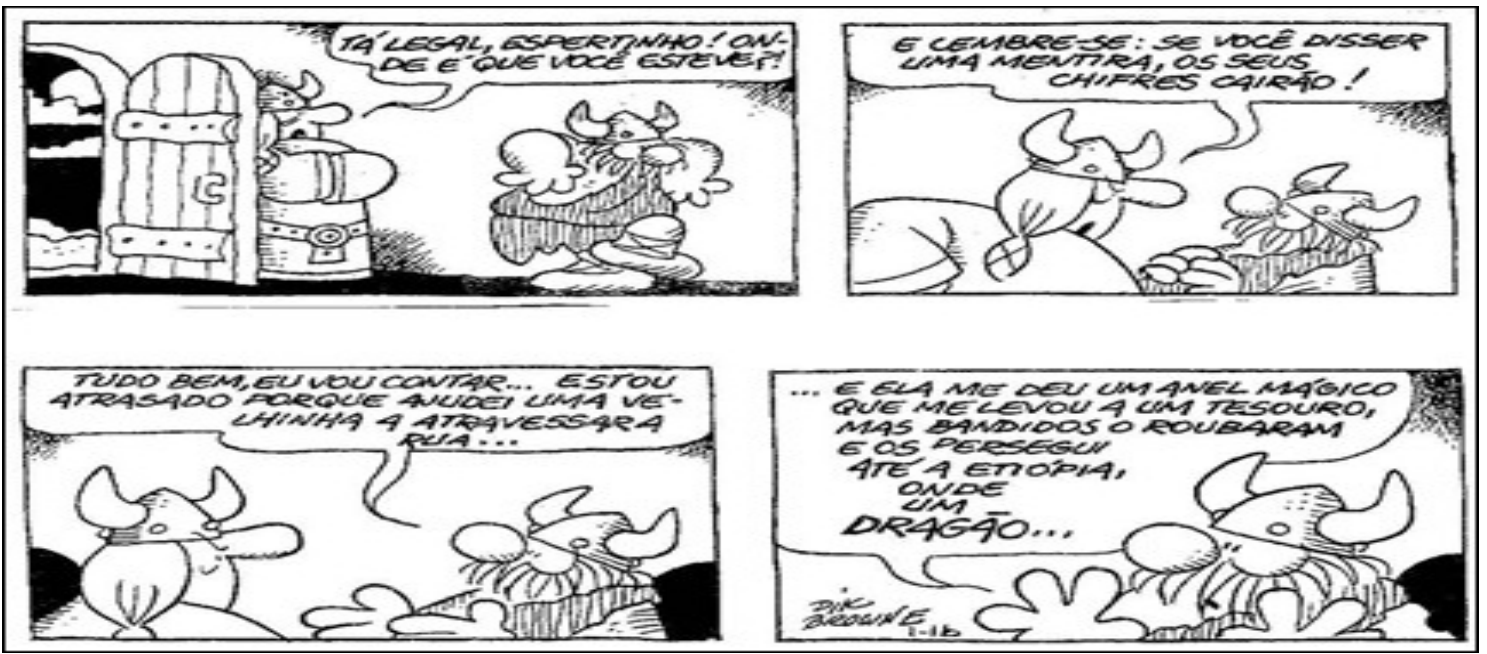

Fonte - HERNANDES, Roberta. MARTIN, Vima Lia. Língua Portuguesa. Curitiba: Positivo, 2013, p. 161.

Na tirinha acima, ao receber o marido, Helga utiliza um registro informal da língua para cobrar dele explicações sobre onde esteve: "Tá legal, espertinho! Onde é que você esteve?!". Isso se dá porque eles têm uma relação de intimidade, o que permite a ela fazer um uso linguístico mais espontâneo, menos monitorado. Já Hagar, que se encontra em uma situação desconfortável, de maior tensão psicológica, faz uso de um registro mais formal da língua, como podemos observar no terceiro e, sobretudo, no quarto quadrinho. Sentindo-se pressionado pela mulher, ele utiliza uma forma de linguagem mais cuidada, mais monitorada, para convencê-la a acreditar em sua fantasiosa história, ou seja, a personagem relembra outras histórias e nessa narrativa o uso da língua é mais formal, pois estabeleceu-se desse modo, quer dizer, a língua enquanto prática social se configura de certa maneira e isso é aprendido pelos falantes.

Continuadamente, o livro nos apresenta mais questões que são interessantes e importantes, embora sejam construções distintas em relação ao grau de maior ou menor formalidade, são duas frases legitimas do português brasileiro, passíveis de serem faladas ou escritas pelos usuários da língua. Segue o exemplo abaixo: 
Figura 7: Construções equivalentes no português.

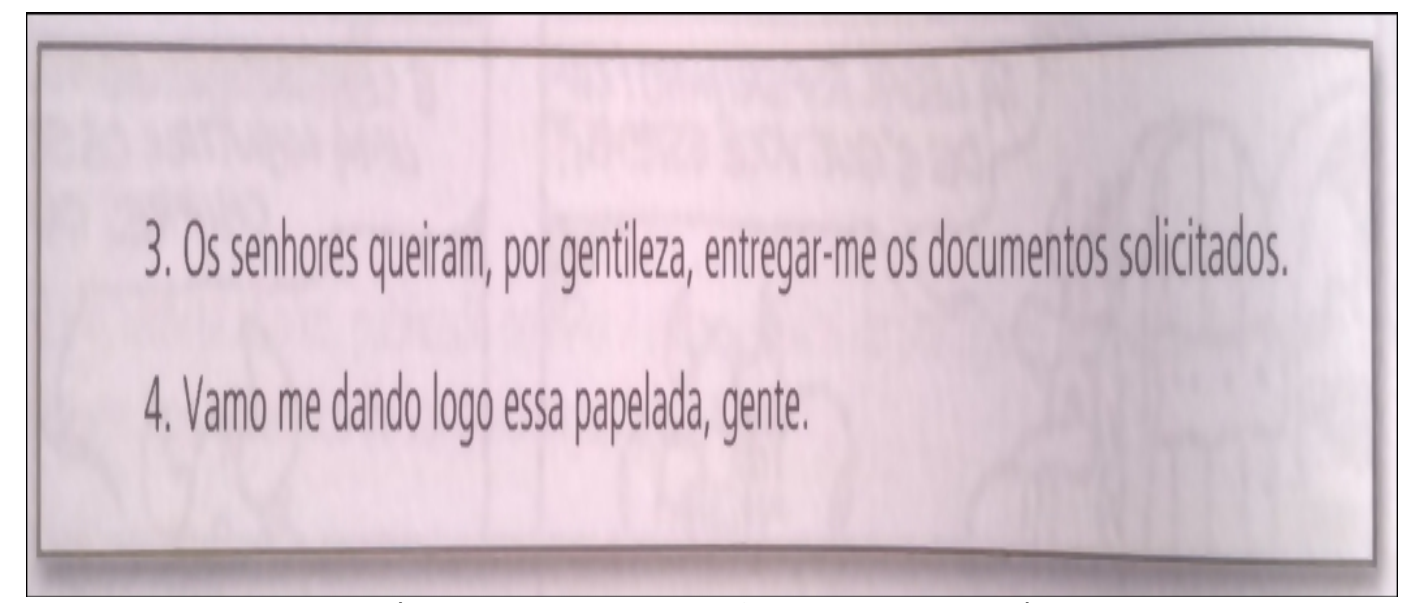

Fonte - HERNANDES, Roberta. MARTIN, Vima Lia. Língua Portuguesa. Curitiba: Positivo, 2013, p. 162.

O livro menciona que são construções equivalentes porque servem para comunicar o mesmo conteúdo informacional, ou seja, "dizem a mesma coisa". Contudo elas dizem de formas diferentes. Ao analisar, vemos que a situação que são usadas são diferentes pelas propriedades das palavras, nessa relação percebemos que uma estrutura se dá ao meio formal, padrão, enquanto a outra forma designa um uso de língua mais coloquial. Significa dizer que esse princípio se faz pela comunicação que exercemos, isto é, através das necessidades comunicativas modificamos nossa forma de fala, se adapta ao contexto em estamos inseridos. Assim, esse sentido produz uma variação adequação linguística, pois já imaginou se precisássemos utilizar a todo momento uma linguagem rebuscada e cheia de arcaísmos nas mais corriqueiras situações de nosso cotidiano? Provavelmente perderíamos a espontaneidade da fala, sem contar que a dinamicidade da comunicação seria prejudicada. A cada umas dessas formas diferentes de uso da língua chamamos de variedades linguísticas, isto é, não existindo uma língua certa ou errada, mas formas diferentes.

Portanto, o que se mostra é que a escola não pode impor o monolínguismo, somente assim, transcorrerá o reconhecimento da existência das variedades na língua, da necessidade de valorização e do respeito dentro e fora da escola, ou seja, "impor a norma de língua culta, desprezando o multilinguismo existente no português brasileiro, estabelecendo noções de "certo" e "errado", o que na verdade não se pode fazer uma vez que "a língua é essencialmente heterogênea, variante e mutante" (BAGNO, 2007, p. 130). 


\section{Considerações finais}

A partir da análise nas coleções de livros didáticos aprovados pelo PNLD, concluímos que o ensino da Língua não dita sobre a variação linguística, na maioria das vezes, também não seguindo os conceitos elaborados pelos Parâmetros Curriculares Nacionais, consequentemente, deixa de contribuir para o ensino das diversidades que ocorrem na língua. Dessa forma, esperamos que os professores reconheçam as comunidades de fala, representadas pelos alunos, não só para saber das variantes presentes, como também para enxergar novas possibilidades de trabalhos que mobilizem todo o grupo/comunidade a uma inclusão social e cultural, esquecendo o preconceito linguístico. Não podemos deixar de situar que o professor tem que estar preparado para explicar ao aluno sobre a língua e suas particularidades. O que se busca, é o respeito às diversidades de fala, presentes na sociedade, pois, sabemos que a língua não se constitui de homogeneidade, ao contrário, ela implica variações, sua heterogeneidade própria e já que o papel do professor e da escola é preparar cidadãos capazes de viver/comunicar em sociedade, é de suma importância que saibamos que a língua nos propiciam variadas formas de fala dependendo do contexto comunicativo em que somos inseridos e que a língua não restringe-se unicamente a norma culta.

Concluímos que as coleções de livros didáticos abordados tiveram contrapontos distintos, pois o Livro Didático Língua Portuguesa (2013) aborda de forma significativa as questões de língua, variação linguística e preconceito linguístico, enquanto o livro didático de Língua Portuguesa: linguagem e interação (2014) não aborda essas respectivas questões. Ou seja, percebemos nos recortes didáticos que os livros que ditam sobre a heterogeneidade da língua contribuem para a compreensão dos fatos de linguagem e acreditamos que só através da difusão do ensino das variações linguísticas as pessoas terão a competência de decidir o modo de fala, trilhar o caminho para transitar em diferentes comunidades linguísticas. Observamos que uma coleção de livros não faz referência em nenhum momento sobre o ensino de língua, variação e preconceito linguístico, da ênfase apenas as normas gramaticais da língua e outra coleção que faz referência, mesmo que suscintamente e superficial, pautado em apenas um capítulo, em nenhum momento em suas seções, textos e atividades restringiu tratar as variações apenas como variedades regionais ou de pessoas não escolarizadas. Dizemos que não é o esperado para um ensino de língua, mas mesmo "acanhado" percebemos as notáveis mudanças em relação a outra coleção. 
Portanto, para ensinar as variações linguísticas ocorrentes na língua Portuguesa, precisase primeiramente ensinar aos alunos, certamente, reconhecer a realidade da língua e buscar um equilíbrio, ou seja, através dos ensinamentos linguísticos sobre as transformações que ocorrem na língua, os professores, precisam mostrar as diversidades que a língua carrega, para que o aluno compreenda suas escolhas. O aluno sabendo previamente sobre os conceitos existentes na língua o ajudará a ampliar seu repertório linguístico, garantindo o acesso a outras comunidades linguísticas, ou seja, a língua tem por finalidade estabelecer a comunicação/interação. Ela não é algo fixo/parado, onde, se aceita apenas uma possibilidade, mas ao contrário, ela é flexível/maleável, adapta-se a cada comunidade de modo diferenciado, a questão é aceitar, admirar e respeitar as diferentes formas de manifestá-la. E esse conhecimento pode ser melhor compreendido na sala de aula com o auxílio do professor e do LD. Infelizmente, constatamos poucas propostas ao discernimento que envolvem o ensino das variações que ocorrem na língua, isto é, na maioria das vezes há um distanciamento muito grande entre as variedades estigmatizadas e as variedades "ditas" de prestígio, não ajudando no combate ao preconceito linguístico existente em nossa sociedade. Por isso reiteramos a importância do conhecimento que o professor deve ter a respeito da língua, variedades e preconceito para poder explicar esses ensinamentos em sala de aula. Também persistimos em livros didáticos de Língua Portuguesa que contenha os ensinamentos desse fenômeno totalmente natural e variável na língua.

Assim, ressaltamos que esta pesquisa não se encerra aqui, ela abre novas indagações, caminhos a serem percorridos, em busca de respostas para contribuir e consolidar o ensino da variação linguística nos livros didáticos visando uma melhor formação dos alunos ao ensino da língua.

\section{Referências}

ABAURRE, M. L. M.; PONTARA, M. Gramática: texto: análise e construção de sentido. São Paulo: Moderna, 2008.

ALMEIDA BARONAS, Joyce Elaine de. Variação linguística na escola: resultados de um projeto. Revista da ABRALIN, v. 13, n. 1, p. 39-62, jan./jun. 2014.

BAGNO, M. A norma oculta: língua e poder na sociedade brasileira. São Paulo: Parábola. Editorial, 2003. Editorial, 2007.

Nada na língua é por acaso: por uma pedagogia da variação linguística. São Paulo: Parábola Sete erros aos quatro ventos: a variação linguística e ensino de português. São Paulo: Parábola Editorial, 2013. 
BARROS, Adil de J. P. de; LEHFELD, Neide A. de S. Projeto de pesquisa: propostas metodológicas. 14.ed. Petrópolis: Vozes, 1990.

BORTONI-RICARDO, Stella Maris. Educação em Língua Materna: a sociolinguística na sala de aula. São Paulo: Parábola Editorial, 2004.

Manual de Sociolinguística. São Paulo: Contexto, 2014.

BRASIL. Secretaria de Educação Fundamental. Parâmetros Curriculares Nacionais: pluralidade Cultural orientação sexual / Secretaria de Educação Fundamental. Brasília: MEC/SEF, 1997.

DANTE, Luiz Roberto. Livro didático de Matemática: uso ou abuso? In: Em aberto. Brasília, v. 26, n.69, p. 52-58, jan/mar. 1996.

FARACO, Carlos Emílio. MOURA, Francisco Marto de. MARUXO JUNIOR, José Hamilton. Língua Portuguesa: linguagem e interação. 2.ed. São Paulo: Ática, 2014.

FNDE. Fundo Nacional de Desenvolvimento da Educação. Disponível em <http://www.fnde.gov.br> acessado em 10/06/2017.

HERNANDES, Roberta. MARTIN, Vima Lia. Língua Portuguesa. Curitiba: Positivo, 2013.

LABOV, William (1972). Padrões sociolinguísticos. Trad. Marcos Bagno; Marta Scherre e Caroline Cardoso. São Paulo: Parábola, 2008

LAJOLO, Marisa. Livro didático, um (quase) manual de usuário. Campinas: Unicamp, 1996.

LIBÂNEO, José Carlos. Didática: velhos e novos temas. Edição do Autor, maio de 2002.

LIMA, Ricardo Joseh. Variação linguística e os livros didáticos de português. In: MARTINS, Marco Antonio; VIEIRA, Silvia Rodrigues; TAVARES, Maria Alice. (Orgs.). Ensino de português e sociolinguística. São Paulo: Contexto, 2016.

MARTINS, Marco Antonio. VIEIRA, Silvia Rodrigues. TAVARES, Maria Alice. Ensino de português e Sociolinguística. 1.ed., 1 reimpressão. São Paulo: Contexto, 2016.

MATO GROSSO. Área de Linguagens. Cuiabá-MT: Secretaria de Estado de Educação, 2012.

MOLLICA, Maria Cecilia. BRAGA, Maria Luiza. Introdução a sociolinguística: o tratamento da variação. São Paulo: contexto, 2003.

SOARES, Magda. Novas práticas de leitura e escrita: letramento na Cibercultura. Educação e Sociedade, dez. 2002, v. 23. n. 81, p. 141-160.

SOUZA, D. M. Autoridade, Autoria e Livro didático. In: CORACINI, M. J. R. F. (Org.) Interpretação, Autoria e Legitimação do Livro didático. Campinas, SP: Pontes, 1999. 